\title{
Reflex sympathetic dystrophy
}

\author{
Elisabeth Paice
}

\begin{abstract}
Whittington Hospital, London N19 5NF Elisabeth Paice, consultant rheumatologist
\end{abstract}

$B M 7$ 1995;310:1645-8
FIG 1-Reflex sympathetic dystrophy of the right hand after a fall, with no bony injury. The affected hand is discoloured and the fingers are swollen

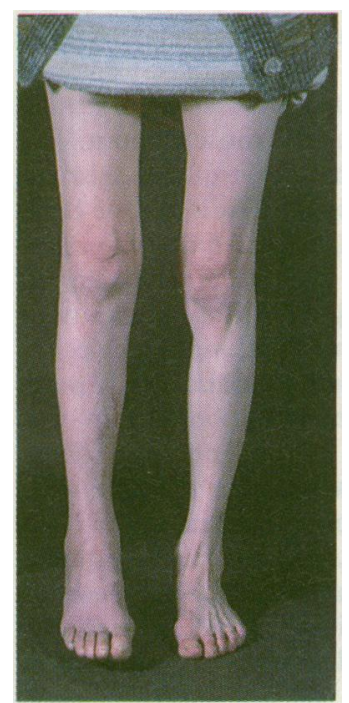

FIG 2-Reflex sympathetic dystrophy of the right foot occurring spontaneously in pregnancy. The patient responded to guanethidine blocks
Reflex sympathetic dystrophy indicates the syndrome of a painful, swollen, discoloured, abnormally sensitive, and useless extremity, usually developing after trauma, and first described as a complication of gunshot wounds in the American Civil War. ${ }^{1}$ Even after 130 years, we still cannot agree what to call it, do not understand what causes it, and do not know how best to treat it.

\section{Definition}

The term reflex sympathetic dystrophy, or the reflex sympathetic dystrophy syndrome, seems to be preferred by those writing in English, algodystrophy by those writing in French, and Sudeck's atrophy by those writing in German or referring to a late atrophic

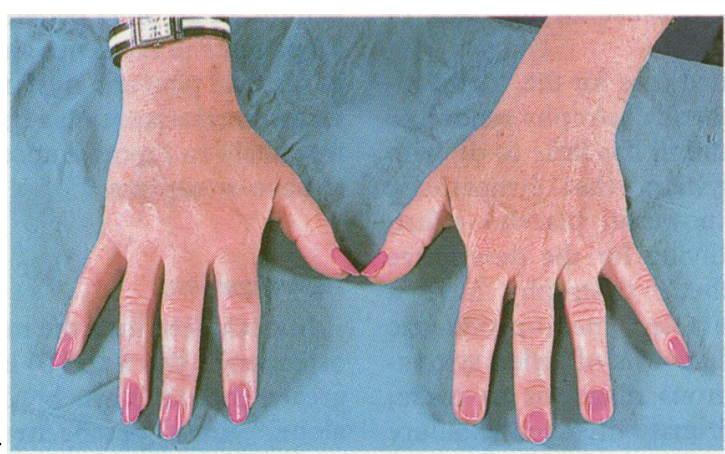

phase of the condition. Definitions and clinical criteria abound. ${ }^{2}$ The International Association for the Study of Pain produced the following definition: "continuous pain in a portion of an extremity after trauma which may include fracture but does not involve a major nerve, associated with sympathetic hyperactivity." 3 Kozin, whose criteria for diagnosis are most widely quoted, considered it essential to recognise that pain may be the only manifestation of the reflex sympathetic dystrophy syndrome and also included patients with vasomotor or sudomotor changes without pain or tenderness as possibly having the syndrome. ${ }^{4}$ The consensus report of an ad hoc committee of the American Association for Hand Surgery considered that the term reflex sympathetic dystrophy was used too loosely to be valuable and errors of under and over diagnosis occurred. ${ }^{5}$ It agreed on the following definition: a pain syndrome in which the pain is accompanied by loss of function and evidence of autonomic dysfunction (figs 1-3).

\section{Aetiology}

Reflex sympathetic dystrophy usually follows trauma, however trivial, or a variety of other triggers,

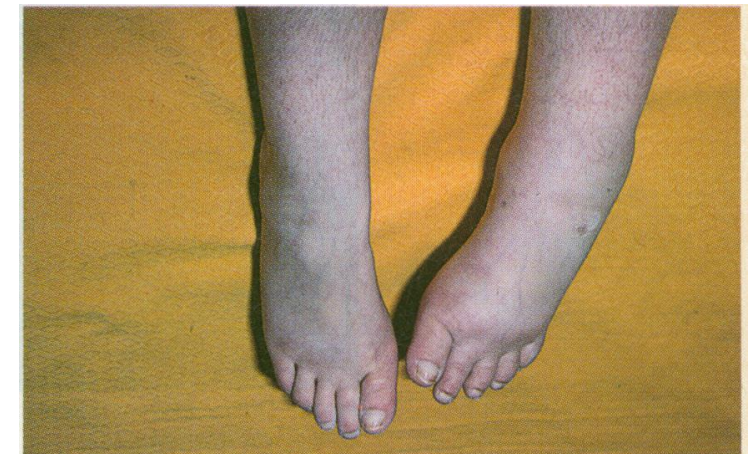

FIG 3-Reflex sympathetic dystrophy of the left foot. The patient previously had the same syndrome in the other foot and in one hand

such as stroke, shingles, and myocardial infarction. ${ }^{4}$ It has been suggested that reflex sympathetic dystrophy results from an initial vasomotor reflex spasm, occurring after injury, followed by a loss of vascular tone leading to vasodilatation and rapid bone resorption. Increasing immobility then leads to decreased circulation, leading eventually to fibrosis and shortening of ligaments. ${ }^{6}$ Various theories have been offered to explain the vasomotor changes, including an abnormality in the central nervous system within the internuncial neuron pool of the substantia nigra where a "self exciting system" develops." Others have suggested abnormalities of the peripheral nervous system, with abnormal synapses between efferent sympathetic nerves and afferent sensory nerves, or sensitised peripheral nerves discharging spontaneously. ${ }^{8}$

The view that the condition is caused by an abnormality of the sympathetic system is widely challenged, and a variety of other explanations have been offered. ${ }^{9}$ If there is increased sympathetic activity in the affected limb it should be possible to find increased concentrations of adrenaline or noradrenaline. It seems that the reverse is the case. In 26 patients with features of reflex sympathetic dystrophy, venous blood was collected from painful and unaffected limbs and levels of plasma adrenaline and noradrenaline and its intracellular metabolite, 3,4-dihydroxyphenylethyleneglycol, were measured. Plasma concentrations of the metabolite were lower on the painful side. Concentrations of plasma noradrenaline were also lower on the painful side in patients with abnormal skin sensitivity and in those with hyperhidrosis in the affected hand or foot. These findings suggest that sweating and changes in peripheral blood flow in reflex sympathetic dystrophy may result from supersensitivity to sympathetic neurotransmitters rather than overreactivity of the sympathetic system. ${ }^{10}$ Other studies showed that vasoconstrictor tone was reduced rather than increased 
in symptomatic areas, ${ }^{11}$ and resting sympathetic discharge was not increased. ${ }^{12}{ }^{13}$ Susceptible people may have a problem with natural opioid modulation. After injury there is normally an increased output of opioids from regional sympathetic ganglia, which prevents excessive autonomic activity in an injured limb. If this fails, dystrophic changes may occur either because of passive complications of disuse associated with pain or as a result of more active processes..$^{14}$

Psychological disturbance has been postulated as a predisposing factor, with reflex sympathetic dystrophy patients described as psychologically peculiar. ${ }^{15}{ }^{16}$ In 42 patients, investigators observed different frequency

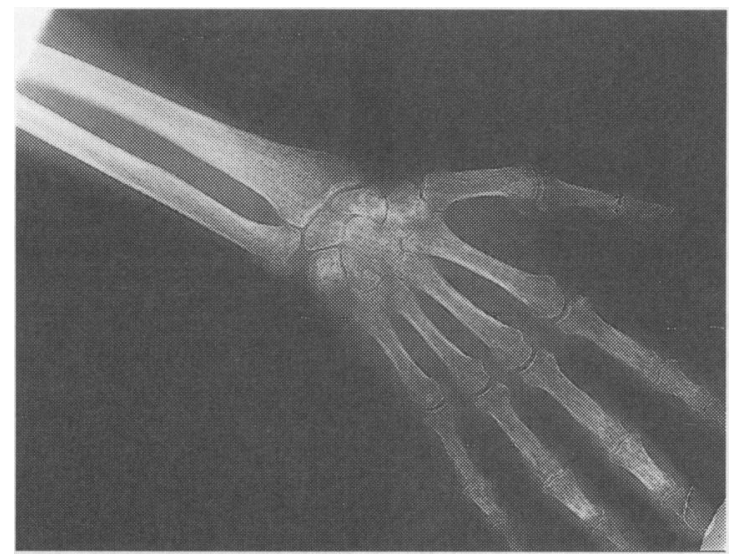

FIG 4-Diffuse spotty osteopenia in the hand of a patient with reflex sympathetic dystrophy

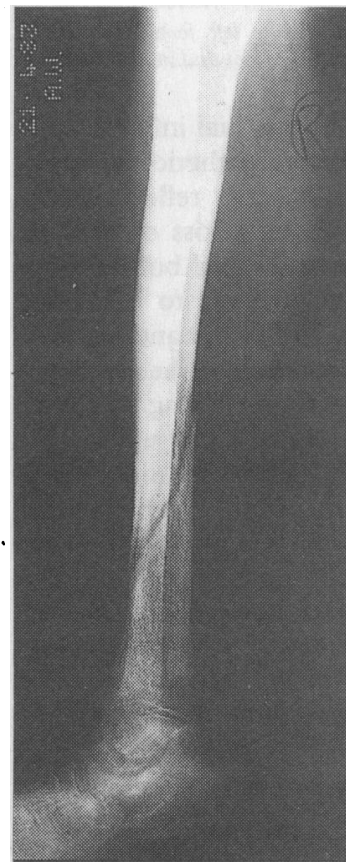

FIG 5-Profound osteopenia in an elderly woman developing reflex sympathetic dystrophy after a fracture. She responded dramatically to calcitonin injections

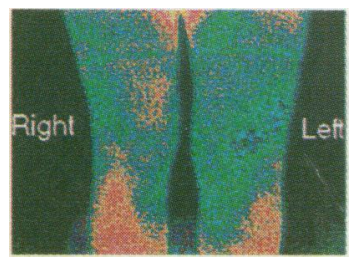

FIG 6-Thermography showing $1^{\circ} \mathrm{C}$ cooler knee on left, the side affected by reflex sympathetic dystrophy (courtesy of $\operatorname{Dr} A G$ White) distributions for the personality traits self satisfaction, rigidity, and somatisation than in controls. ${ }^{17}$ Others have criticised such studies because of the lack of controlled or prospective data. ${ }^{18}$

Ochoa makes an impassioned case for the "demystification" of the reflex sympathetic dystrophy syndrome and acceptance that the condition has little to do with the sympathetic nervous system, that sympathetic blockade works only by a powerful placebo effect, and that most patients qualifying for the descriptive diagnosis of reflex sympathetic dystrophy have a distinct, potentially treatable neuropsychiatric disorder. He describes the diagnosis of reflex sympathetic dystrophy as a dangerous diagnosis to make, condemning the patient to ultimate therapeutic failure after an initial bonanza, or to migration to another part of the body. ${ }^{19}$

\section{Staging}

Three stages of severity have been described. ${ }^{20}$ Stage I consists of pain out of proportion to any injury, abnormal sensitivity, swelling, vasomotor and sudomotor changes, and diffuse osteoporosis. Stage II is characterised by persistence of pain and disability with increasing dystrophy. Stage III is marked by skin and subcutaneous tissue atrophy and contractures. However, a study of 829 patients referred over eight years to a tertiary referral centre was not able to confirm this chronological progression ${ }^{21}$ but found that patients could be divided into "warm" or "cold" on th basis of relative skin temperature in the affected limb, and the longer they had reflex sympathetic dystrophy the more likely they were to have a cold limb. Despite this, $13 \%$ of patients examined very early in the condition had a cold limb, and warm limbs were found in patients who had had reflex sympathetic dystrophy for many years. Tissue atrophy was a rare and late finding in this study. The authors devised their own criteria for inclusion, consisting of unexplained pain, vasomotor changes, and aggravation by use. Requiring

\section{Summary points}

- Reflex sympathetic dystrophy is a pain syndrome, usually affecting an extremity

- It usually follows trauma, however trivial

- Swelling, discoloration, temperature changes, abnormal sensitivity, sweating, and loss of function are typical features of the syndrome

- Radiographs usually show osteopenia of the affected part

- If treatment is neglected, permanent disability may result

- Early recognition, pain control, and mobilisation are associated with a good prognosis

- Large scale controlled trials of the invasive treatments in common use have not been carried out

the presence of osteopenia would have led to rejection of $70 \%$ of their cases.

\section{Children}

In a series of 70 children with reflex sympathetic dystrophy, the average age was 12.5 , girls outnumbered boys in a ratio of almost $6: 1$, and a leg was affected in 61 cases. The average time from the initial injury to the diagnosis was one year. Conservative treatment with physical therapy, transcutaneous electrical nerve stimulation, and psychological therapy was effective in 40 patients. Sympathetic blocks were helpful for 28 of 37 patients treated. Thirty eight of the 70 patients in the series continued to have some degree of residual pain and dysfunction..$^{22}$ The most important factor in treatment may be mobilisation. ${ }^{23}$ Children are less likely to report antecedent trauma, and less likely to have osteopenia. ${ }^{24}$

\section{Investigations}

Sudeck described the radiographic changes of spotty osteopenia (figs 4 and 5) in 1900.25 The osteoporosis is greater than that which would be expected from disuse alone. ${ }^{26}$ In a prospective study of 60 consecutive patients who had suffered unilateral fractures of the tibial shaft, 18 patients showed signs of reflex sympathetic dystrophy at the time of bone union. Patients with reflex sympathetic dystrophy lost significantly more bone mineral density than did those without. The degree of loss was independent of type of management and of the time to fracture union. ${ }^{27}$ Radioisotope bone scanning may be helpful in diagnosis. Adults with reflex sympathetic dystrophy have a characteristic delayed bone scan pattern consisting of diffusely increased uptake with juxta-articular accentuation, but in children decreased uptake at the symptomatic site is more common. ${ }^{28}$ Three phase technetium bone scan was used in the investigation of 63 patients with unexplained arm pain. Twenty six per cent of these were sund to have a definite or probable reflex sympathetic dystrophy on Kozin's criteria. The predictive value of the test was assessed retrospectively. The three hour delayed image showed a sensitivity of $50 \%$; specificity of $92 \%$; positive predictive value of $67 \%$, and negative predictive value of $\mathbf{8 4 \%}$. This was not improved when data from the blood flow or pool phase were used. Duration of symptoms less than six months or age more than 50 years substantially increased the sensitivity and positive predictive value of the scan. ${ }^{29}$ Thermography offers a sensitive method for detecting 


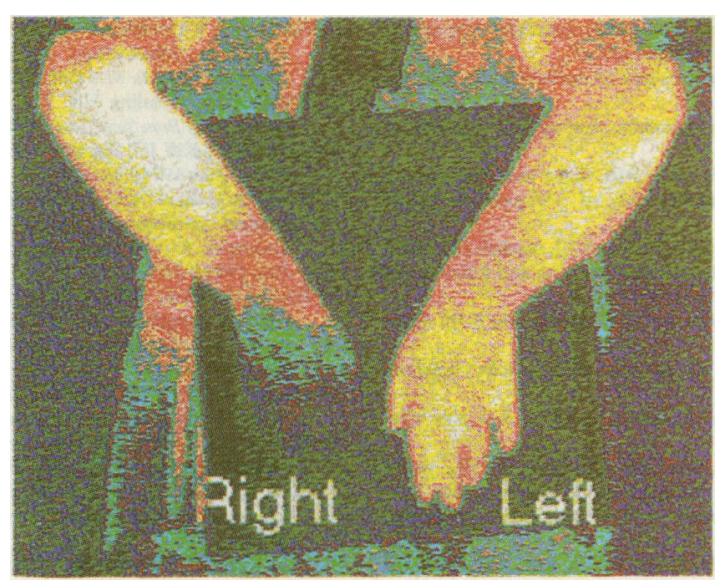

FIG 7-Thermography of a patient who sustained a blow on the right elbow and developed a reflex sympathetic dystrophy of the right arm and hand. Temperature is increased at the site of the injury, and decreased in the hand (courtesy of $\operatorname{Dr} A G$ White)

and recording temperature differences between affected and unaffected limbs.

\section{Treatment}

Most authors emphasise the importance of physiotherapy in the prevention and treatment of the disease. A study of 54 patients with reflex sympathetic dystrophy compared exercises and cryotherapy either with or without galvanic stimulation, and reported a significant therapeutic effect in both treatment groups. ${ }^{30}$ Two thirds of 489 patients who had received physiotherapy for reflex sympathetic dystrophy reported temporary exacerbation in the hours following treatment, ${ }^{24}$ No placebo-controlled studies of physiotherapy have been performed.

Sympathetic blockade has been the most popular therapeutic approach since the $1930 \mathrm{~s},{ }^{31}$ initially induced surgically and later by intravenous guanethidine blockade. ${ }^{32}$ Controlled studies of any size are few. The efficacy of guanethidine versus reserpine was compared in 12 patients, 10 of whom had previous stellate or lumbar sympathetic blocks, in a placebo controlled, double blind, cross over study. Each patient successively received $20 \mathrm{mg}$ guanethidine in $50 \mathrm{ml} 0.5 \%$ lignocaine, $1.25 \mathrm{mg}$ reserpine in $50 \mathrm{ml}$ $0.5 \%$ lignocaine, and $50 \mathrm{ml} 0.5 \%$ lignocaine with a one week interval between drugs, followed by continued treatment with whichever treatment had seemed the most effective. Follow up lasted for a minimum of six months. Changes in pain intensity for the first three days did not differ significantly among guanethidine, reserpine, and control groups. Pain was relieved for two to 14 months in two patients receiving reserpine, one receiving guanethidine, and none receiving lignocaine. None of the patients experienced permanent relief. No difference was found between reserpine and guanethidine. ${ }^{33}$

A placebo controlled study of bretylium (a guanethidine-like drug which inhibits the release of noradrenaline from adrenergic nerve endings) was performed on 12 patients with reflex sympathetic dystrophy who received transient pain relief from stellate ganglion blocks. or lumbar sympathetic blocks. Each patient received two control treatments ( $0.5 \%$ lignocaine) and two treatments with $0.5 \%$ lignocaine and bretylium $1.5 \mathrm{mg} / \mathrm{kg}$ in a randomised, double blind fashion. Five patients failed to complete. Bretylium and lignocaine provided more than $30 \%$ pain relief for a mean of 20.0 (SD 17.5) days, whereas lignocaine alone provided relief for only $2 \cdot 7$ (3.7) days (Mann-Whitney $\mathrm{U}$ test, $\mathrm{P}<0.001){ }^{34}$

Ketanserin was assessed against placebo in a double blind, cross over study of 16 patients with chronic peripheral burning pain. Nine of these had signs of reflex sympathetic dystrophy. All patients underwent four intravenous regional treatments, two with ketanserin and two with placebo. In those patients with reflex sympathetic dystrophy, ketanserin and not placebo provided sustained pain relief. In patients who did not fulfil the criteria for reflex sympathetic dystrophy no significant relief was seen with placebo or ketanserin. ${ }^{35}$

Uncontrolled studies abound, offering subjective and objective evidence of improvement with a variety of treatments. ${ }^{36-39}$ A retrospective review of 199 patients with sympathetic reflex dystrophy of the foot compared a variety of treatments; calcitonin (177 patients) improved or cured $62 \%$ of those treated. Regional sympathetic blockade with guanethidine (49 patients) provided $80 \%$ improvement or cure. All patients in this study were cured, $75 \%$ in less than a year. Normal activities were possible five months after the end of treatment in both groups. Neither psychological disturbance or work related injury affected the outcome. ${ }^{40} \mathrm{~A}$ total of 513 regional intravenous guanethidine blocks were carried out in 125 cases of reflex sympathetic dystrophy; a positive result occurred in 90 after a mean of $4 \cdot 5(1 \cdot 7)$ blocks. ${ }^{41}$

\section{Conclusion}

Most authors emphasise the importance of early, confident, multidisciplinary treatment of reflex sympathetic dystrophy, a condition which untreated can lead to devastating long term disability. Unfortunately we have little objective evidence on which to base a rational treatment plan. It is surely time for large multicentre prospective placebo controlled studies to look at the effect of early mobilisation after fracture, the various forms of physiotherapy, and the variety of treatments available.

Thermography was performed by $\mathrm{Mr}$ Kevin Howell at the Royal Free Hospital Rheumatology Research Unit. Other photographs were prepared by the photography department of the Whittington Hospital NHS Trust.

1 Mitchell SW, Morehouse GR, Keen WW. Gunshot wounds and other injuries of nerves. New York: Lippincott, 1864.

2 Doury P. Algodystrophy. Reflex sympathetic dystrophy syndrome. Clin Rheumatol 1988;7:173-80.

3 International Association for the Study of Pain, Subcommittee on Taxonomy. Descriptions of chronic pain syndromes and definitions of pain terms. Pain 1986 (suppl 3):S28-30.

1986 (suppl 3):S28-30.
4 Kozin F. Reflex sympathetic dystrophy syndrome: a review. Clin Exp Rheumatol 1992;10:401-9.

5 Amadio PC, Mackinnon SE, Merritt WH, Brody GS, Terzis JK. RSDS consensus report of an ad hoc committee of the American Association fo Hand Surgery on the definition of RSDS. Plast Reconstruct Surg 1991;87: 371-5.

6 Poplawski ZJ, Wiley AM, Murray JF. Post-traumatic dystrophy of the extremities: a review and trial of treatment. $\mathcal{f}$ Bone foint Surg $[A]$ 1983;65:642-54.

7 Livingston WK. Pain mechanisms. New York: Macmillan, 1947.

8 Hooshmand H. Chronic pain: reflex sympathetic dystrophy, prevention and management. Boca Raton, FL: CRC Press, 1993:13-26.

9 Marchinetti P, Lacerenza M, Leracitano D, Canal N. Sensitized nocioceptors in reflex sympathetic dystrophies. Functional Neurology 1989;4:135-40.

10 Drummond PD, Finch PM, Smythe GA. Reflex sympathetic dystrophy: the significance of differing plasma catecholamine concentrations in affected significance of differing plasma catecholamine
and unaffected limbs. Brain 1991;114:2025-36.

11 Christensen K, Henriksen O. The RSDS: an experimental study of reflex christensen K, Henriksen O. The RSDS: an experimental study of reflex
sympathetic control of subcutaneous blood flow in the hand. Scand $f$ Rheumat 1983;12:263-7.

12 Casale $R$, Elam $M$. Normal sympathetic nerve activity in a reflex sympathetic dystrophy with marked skin vasoconstriction. $₹$ Autonom Nerv Syst 1992;41: 215-9.

13 Schott G. Clinical features of algodystrophy: is the sympathetic nervous system involved? Funct Neurol 1989;4:131-4.

14 Hannington-Kiff JG. Does failed natural opioid modulation in regiona sympathetic ganglia cause reflex sympathetic dystrophy? Lancet 1991;338: $1125-7$.

15 Egle UT, Hoffman SO. Psychosomatic correlations of sympathetic reflex dystrophy (Sudeck's disease). Review of the literature and initial clinical dystrophy (Sudeck's disease). Review of the literature
results. Psychother Psychosom Med Psychol 1990;40:123-35.

16 Van Houdenhove B, Vasquez G, Onghena P, Stans L, Vandeput C, Vermaut G, et al. Etiopathogenesis of RSD: a review and biopsychosocial hypothesis.

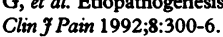

17 De Vilder J. Personality of patients with Sudeck's atrophy following tibial fracture. Acta Orthop Belg 1992;58(suppl 1):252-7. 
18 Lynch ME. Psychological aspects of reflex sympathetic dystrophy: a review of the adult and paediatric literature. Pain 1992;49:337-47.

19 Ochoa JL. Reflex sympathetic dystrophy: a disease of medical understanding. Clin ₹ Pain 1992;8:363-9.

20 Bonica IJ. Causalgia and other reflex sympathetic dystrophies. Advances in Pain Research and Therapy 1979;3;141-66.

21 Veldman PHJM, Reynen HM, Arntz IE, Goris RJA. Signs and symptoms of reflex sympathetic dystrophy: prospective study of 829 patients. Lancet 1993;342:1012-6.

22 Wilder RT, Berde CB, Wolohan M, Vieyra MA, Masek BJ, Micheli LJ. Refle sympathetic dystrophy in children. Clinical characteristics and follow-up of seventy patients. F Bone foint Surg $[A]$ 1992;74:910-9.

23 Silber TJ, Massoud M. RSDS in children and adolescents. Am $f$ Dis Child 1988; 142:1325-30.

24 Dietz FR, Mathews KD, Montgomery WJ. RSD in children. Clin Orthopaed Rel Res 1989;258:225-31.

25 Sudeck P. Ober die akute entzündliche Knockenaptrophie. Arch Klin Chir 1900;62:147.

26 Genant HK, Konin F, Bekerman C, McCarty DJ, Sims J. The reflex sympathetic dystrophy syndrome: a comprehensive analysis using finesympathetic dystrophy syndrome: a comprehensive analysis using fine-
detail radiography, photon absorptiometry and bone and joint scintigraphy. Radiology 1975;117:21-32.

27 Saranagi PP, Ward AJ, Smith EJ, Staddon GE, Atkins RM. Algodystrophy and osteoporosis after tibial fractures. 7 Bone foint Surg [B] 1993;75:450-2.

28 Goldsmith DP, Vivino FB, Eichenfield AH, Athreya BH, Heyman S. Nuclear imaging and clinical features of childhood reflex neurovascular dystrophy: comparison with adults. Arth Rheum 1989;32:480-5.

29 Werner R, Davidoff G, Jackson MD, Cremer S, Ventocilla C, Wolf L. Factors affecting the sensitivity and specificity of the three-phase technetium bone scan in the diagnosis of reflex sympathetic dystrophy syndrome in the upper extremity. 7 Hand Surg 1989;14:520-3.
30 Fialka V, Wickenhauser J, Engel A, Schneider B. Sympathetic reflex dystrophy. Effectiveness of physical therapy treatment of Sudeck's dystrophy. Effectiveness of physical ther
syndrome. Forschr Med 1992;110(9):146-8.

31 Schutzer SF, Gossling HR. The treatment of reflex sympathetic dystrophy syndrome. F Bone foint Surg $[A]$ 1984;66:625-9.

32 Hannington-Kiff JG. Intravenous regional sympathetic block with guanethidine. Lancet 1974; i:1019-20.

33 Rocco AG, Kaul AF, Reisman RM, Gallo JP, Lief PA. A comparison of regional intravenous guanethidine and reserpine in reflex sympathetic dystrophy. A controlled, randomized, double-blind crossover study. Clin $f$ Pain 1989;5:205-9.

34 Hord AH, Rooks MD, Stephens BO, Rogers HG, Fleming LL. Intravenous regional bretylium and lidocaine for treatment of reflex sympathetic dystrophy: randomized, double-blind study. Anesthesia and Analgesia 1992;74:818-21.

35 Hanna MH, Peat SJ. Ketanserin in reflex sympathetic dystrophy. A doubleblind placebo controlled cross-over trial. Pain 1989;38:145-50.

36 Nielsen FB, Olesen AS. Guanethidine blockade for palliative treatment in reflex dystrophy. Ugeskr Laeger 1992;154:1500-2.

37 Field J, Monk C, Atkins RM. Objective improvements in algodystrophy following regional intravenous guanethidine. $f$ Hand Surg 1993;18: 339-42.

38 Poplawski ZJ, Wiley AM, Murray JF. Posttraumatic dystrophy of the extremities. F Bone foint Surg 1983;65(A):642-55.

39 Solarova $P$, Kunev $K$. The calcitonin treatment of patients with algodystrophy. Vutreshni Bolesti 1990;29(5):102-5.

40 Eulry F, Aczei F, Vasseur P, Thomas E, Pattin S, Doury P. L'algodystrophie du pied. A propos de 199 observations. Rev Rheum 1990;57:351-6.

41 Eulry F, Lechevalier D, Pats B, Alliaume C, Crozes P, Vasseur P, et al. Regional intravenous guanethidine blocks in algodystrophy. Clinical Rheumatology 1991;10:377-83.

\title{
Lesson of the Week
}

\section{Reflex sympathetic dystrophy in children}

\author{
Adrian R Lloyd-Thomas, Gillian Lauder
}

Reflex sympathetic dystrophy also occurs in children, commonly girls; early diagnosis gives the best chance for treatment
Department of Paediatric Anaesthesia, Great Ormond Street Hospital for Children NHS Trust, London WC1N 3JH Adrian R Lloyd-Thomas, consultant in paediatric anaesthesia and pain control Gillian Lauder, registrar

Correspondence to: Dr Lloyd-Thomas.
Reflex sympathetic dystrophy is well recognised in adults. It occurs in children but is rarely mentioned in paediatric textbooks. Children presenting with painful limbs often have many investigations and the diagnosis may be considerably delayed. This results in prolonged distressing pain for the child, anxiety for parents, and difficulty with treatment. We describe four cases to show the characteristics of the disease in children.

\section{Case reports} CASE 1

An 11 year old athletic girl presented to this hospital with a 10 week history of increasing pain in her right leg. She had first seen her general practitioner with pain over the tibial tubercle of her right knee but no history of trauma. Her local orthopaedic service had diagnosed Osgood-Schlatter's disease and she had been advised to rest and use crepe bandage and elasticated tubular bandage.

Five days later her leg became cold and blue below the knee, with burning pain radiating from the knee to the foot. Deep vein thrombosis was diagnosed and she was treated with anticoagulant drugs. After a week anticoagulant treatment was stopped, but the leg continued to be painful, cold, and blue when in a dependent position. A full length plaster of Paris cast was applied in an attempt to relieve the pain of the Osgood-Schlatter's disease, but within days the symptoms were worse, affecting her whole leg up to mid-thigh. The blueness resolved only when her leg was elevated. The plaster of Paris was removed, but by this stage the pain was so severe that she would not put her foot on the ground and she was confined to a wheelchair.

On first examination at this hospital the leg was noted to be cold and blue and the foot oedematous. She had allodynia (pain provoked by a stimulus that does not normally cause pain) and hyperaesthesia up to her mid-thigh. Calf and quadriceps muscles were wasted, but results from neurological examination were other- wise normal. Ultrasound scanning of the abdomen, radiography of the legs, venography, and arterial Doppler studies, all performed at the referring hospital, had given normal results; magnetic resonance imaging had shown changes compatible with OsgoodSchlatter's disease. Thermography with the thermal stress test gave results compatible with reflex sympathetic dystrophy. ${ }^{1}$

She was given four intravenous regional guanethidine blocks and intensive physiotherapy every week to encourage mobilisation of the leg. At the end of one month's treatment she was walking normally with no pain in the leg, and all the vascular changes and oedema had gone. Moreover, she was able to begin playing sport once more.

\section{CASE 2}

A 9 year old athletic girl presented to her general practitioner with a 48 hour history of sudden onset of pain in the calf after playing sport at school. Initially strain was diagnosed and she was advised to rest and wear a support bandage. The pain failed to resolve; it did not respond to analgesics, and after five days the leg became blue when in a dependent position. She was referred to her local hospital, where extensive investigations (radiography, Doppler ultrasonography, magnetic resonance imaging, and blood testing) all gave normal results. The pain worsened until she was unable to put her foot on the ground.

When seen at this hospital she had allodynia and dysaesthesia and paraesthesia up to her mid-thigh; her leg was cold and blue when in a dependent position. She had oedema of the foot and there was some wasting of thigh and calf muscles. Her pulses were normal and there was no neurological deficit. She was prescribed four intravenous regional guanethidine blocks weekly and twice daily physiotherapy. After only two blocks she walked normally and all symptoms were resolved.

\section{CASE 3}

A 13 year old athletic girl presented to this hospital 